\title{
Current Sensor in PCB Technology
}

\author{
Pavel Ripka, Member, IEEE, Jan Kubik, Maeve Duffy, William Gerard Hurley, Senior Member, IEEE, and \\ Stephen O'Reilly
}

\begin{abstract}
A novel dc/ac current sensor works on the fluxgate principle. The core in the form of a $7 / 10-\mathrm{mm}$ ring made of electrodeposited permalloy is sandwiched in the middle of a printed circuit board (PCB), whereas the sensor excitation winding is also integrated in the copper layers of the PCB. To lower the sensor power consumption, the excitation winding was tuned by a parallel capacitor. The peak-peak/rms ratio of 5.2 was achieved for the excitation frequency of $25 \mathrm{kHz}$. The open-loop sensor has 100-mV/A sensitivity; the characteristics have a linearity error of $10 \%$ and hysteresis below $0.1 \%$ in the $1-A$ range.
\end{abstract}

Index Terms-Current sensor, fluxgate, magnetic sensor.

\section{INTRODUCTION}

$\mathbf{S}$ IMPLE galvanically isolated dc/ac current sensors are required for switching-mode power supplies, power management systems in cars, solar battery systems, and many other applications. Contactless current sensors should be geometrically selective, i.e., sensitive to measured currents, and resistant against interference from other currents and external fields. The most convenient way to guarantee selectivity is to employ a closed magnetic circuit with a measuring conductor inside [1].

Traditional current sensors are based on the placement of a Hall element in the airgap of a magnetic yoke. To improve the linearity, the measured current must be compensated. These devices have a limited zero stability given by the Hall sensor offset: typical offset drift of a 50-A sensor in the $0{ }^{\circ} \mathrm{C}-70{ }^{\circ} \mathrm{C}$ range is $500 \mathrm{~mA}$. Hall current sensors are also sensitive to external magnetic fields and nearby currents due to the magnetic leakage associated with the airgap in the magnetic circuit. Hall current sensors are in general suitable for larger currents $(>\sim 10 \mathrm{~A})$, for which the device precision is typically $1 \%$ for uncompensated sensors and $0.5 \%$ for compensated types [2].

Coreless magnetoresistive (MR) current sensors are based on an AMR bridge that is made insensitive to external fields but sensitive to measured current through the primary bus bar [3]. Nonideal balance of the sensor results in unwanted sensitivity to nearby currents. More precise coreless current sensors use a circular array of Hall probes or magnetoresistors around the measured conductor [4]-[6]. Similar sensors using the giant magne-

Manuscript received August 29, 2003; revised January 7, 2004. The associate editor coordinating the review of this paper and approving it for publication was Dr. Andre Bossche.

P. Ripka and J. Kubik are with the Czech Technical University, Department of Measurement Technicka 2, 166 Praha 6, Czech Republic 16627 (e-mail: ripka@feld.cvut.cz; kubikj@feld.cvut.cz).

M. Duffy and W. G. Hurley are with the Department of Electronic Engineering, National University of Ireland, Galway, Ireland (e-mail: maeve.duffy@nuigalway.ie; wghurley@ieee.org).

S. O'Reilly is with the National Microelectronic Research Center, "Lee Maltings” Prospect Row, Cork, Ireland (e-mail: stephen.oreilly@nmrc.ie).

Digital Object Identifier 10.1109/JSEN.2005.845187 toresistance effect (GMR) were recently reported. Devices developed by NVE use flux guides to increase the sensitivity of two GMR magnetoresistors in the full bridge, whereas the other two are shielded. Also, unshielded GMR gradiometers can be used for current sensing [7], [8]. Another approach is to use biasing magnetic foil [9] or flat biasing coil [10].

Magneto-optical current sensors or current transformers are based on the Faraday effect. The main difficulties of these sensors (such as temperature dependence) are suppressed by the recently introduced method of direct registration of the domain wall motion [11].

DC current transformers and current comparators are based on the fluxgate effect. A similar low-cost current transducer using a ferrite core was developed by Pross et al. [12]. Fluxgate dc current sensors are manufactured as modules, with excitation and processing electronics, for measurement ranges between 40 and 200 A. The accuracy of a typical $40-\mathrm{A}$ module is $0.5 \%$, the linearity is $0.1 \%$, and the current temperature drift is less than $30 \mathrm{~mA}(-25$ ${ }^{\circ} \mathrm{C}-70{ }^{\circ} \mathrm{C}$ ) [13]. The magnetic core (normally in the shape of a ring) is periodically saturated by a symmetrical ac excitation current. The core magnetization characteristic is also symmetrical; thus, in the absence of measured current, the core flux and the induced voltage are symmetrical and contain only odd harmonic components. The measured dc/ac current flows in a single conductor through the ring center; the sensitivity can be improved by increasing the number of turns of the measured conductor, until the increased insertion impedance has no effect on the measured circuit. The core flux associated with the measured current shifts the magnetization characteristic and introduces asymmetry in the induced voltage waveform, which in turn gives rise to even harmonics. Detection of second harmonics by a synchronous detector is the most popular method for output signal processing, but peak detection and other methods are available. Fluxgate current sensors are the most accurate and geometrically selective of sensor types, but they are bulky, expensive, and powerconsuming. They can also be fabricated as clamps [6].

An integrated fluxgate thin-film current sensor was developed for an overcurrent detector [14]. The first fluxgate current sensor in printed circuit board (PCB) technology was described by Gijs et al. [15], [16]. Their sensor had a single winding of 36 turns formed on a toroidal core made of amorphous magnetic foil. They achieved 10-mV/A sensitivity and ranges up to $5 \mathrm{~A}$.

An overview of the basic parameters of existing contactless low dc current sensors is given in Table I. These parameters are functions of size, power consumption, and price; only "typical" values are given for each technology to allow the reader to compare this work with other technologies.

This paper describes the design of the first prototype of a fluxgate current sensor with an electroplated core in PCB technology. 
TABLE I

Overview of Low-Current Contactless DC CurRent SENSORS

\begin{tabular}{|c|c|c|c|c|c|c|c|c|}
\hline technology & size & sensitivity & power & range & $\begin{array}{l}\text { for } \\
\text { linearity }\end{array}$ & hysteresis & $\begin{array}{l}\text { offset } \\
\text { drift }\end{array}$ & noise \\
\hline & $(\mathrm{mm})$ & $(\mathrm{mV} / \mathrm{A})$ & $(\mathrm{mW})$ & (A) & $(\%)$ & $(\mathrm{mA})$ & $(\mathrm{mA})$ & $(\mathrm{mA})$ \\
\hline $\begin{array}{l}\text { Hall } \\
\text { uncompensated }\end{array}$ & $5 . .30$ & 1 & 10 & $10 . .50$ & 1 & 100 & 500 & 5 \\
\hline $\begin{array}{l}\text { Hall } \\
\text { feedback }\end{array}$ & $\begin{array}{|ll|}10 & . . \\
100 & \\
\end{array}$ & 100 & $100 . .1000$ & 50 & 0.2 & 50 & 500 & 10 \\
\hline AMR & 30 & $10 . .100$ & $100 \ldots 300$ & $5 . .50$ & 0.1 & 5 & $30 . .50$ & 10 \\
\hline fluxgate & $20 . .40$ & $10 . .1000$ & $100 . .500$ & $40 . .200$ & 0.1 & 2 & 30 & 5 \\
\hline
\end{tabular}

The core of this low-cost sensor is very small, and it can be easily integrated into the board design. Despite the small volume of magnetic material in the sensor core, a maximum sensitivity of 100 $\mathrm{mV} / \mathrm{A}$ was achieved with a single winding of 40 turns.

\section{PCB SENSOR DESIGN}

A novel dc/ac current sensor was created by technology developed at the National Microelectronics Research Centre (NMRC), Cork, Ireland, for PCB-integrated inductors [17]. The magnetic circuit has the form of a $7-\mathrm{mm} / 10-\mathrm{mm}$ ring made of electrodeposited permalloy. The core is sandwiched between the layers of the PCB. The sensor excitation winding is also integrated into the PCB design: Individual conductor sections in the lower and upper copper layers are connected by vias, thus forming 40 turns with a total resistance of $700 \mathrm{~m} \Omega$. Overall, 1 A of excitation current yields a magnetic field intensity of $1.45 \mathrm{kA} / \mathrm{m}=18$ Oe. The measured current flows in a single conductor through the center of the ring.

The sensor works on the fluxgate principle; excitation current drives the core into periodical saturation. The measured current causes second-harmonic components in the induced voltage [2]. The first sensor prototype uses only a single core with a single winding and no feedback. The basic schematic is shown in Fig. 1. The sensor is excited by a sinewave current from a generator $\mathrm{G}$ with $50-\Omega$ output resistance. In this case, the generator represents an ideal current source, so that the sensor voltage reacts sensitively to the measured current. Thus, the single winding may serve both for excitation and for detection, which makes the sensor design extremely simple and compact. The sensor excitation can be tuned by a parallel capacitor $C_{1}$.

Fig. 2 shows the excitation current and induced voltage for the untuned sensor supplied with a $20-\mathrm{kHz}, 6-\mathrm{V}$ rms sinewave from the 50- $\Omega$ generator. Although the excitation current is a perfect sinewave $\left(I_{\mathrm{rms}}=202 \mathrm{~mA}, I_{p-p}=570 \mathrm{~mA}\right)$ due to the high impedance of the generator, the induced voltage is highly distorted due to the nonlinearity of the magnetization characteristic. If the measured current is zero, the induced voltage is symmetrical [see Fig. 2(b)]. For nonzero measured current, the voltage waveform is nonsymmetrical and it contains even harmonics. When the measured current exceeds $3 \mathrm{~A}$, the excitation current can no longer saturate the core in one polarity - the voltage output decreases, and the sensor is operating out of the linear region [see Section IV, Fig. 8(a)]. The linear region can be extended by increasing the amplitude of the excitation current, but a more effec-

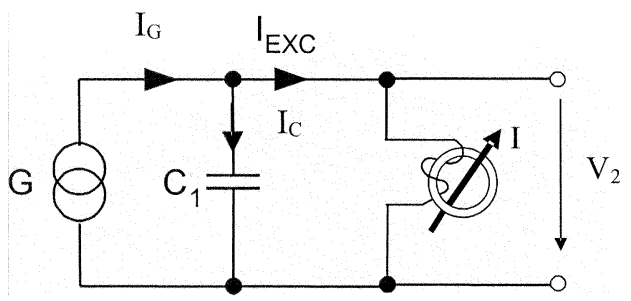

Fig. 1. Fluxgate current sensor tuned in excitation.

tive method is to introduce feedback to compensate the measured current. Feedback also dramatically improves linearity.

Fig. 3 shows the core flux (obtained by numerical integration of the induced voltage), and the corresponding working B-H loop for zero measured current. It is clear that although the excitation current amplitude is high, the core saturation is not sufficient for stable operation. The peaks in the voltage waveform correspond to small values of current when the core permeability is high.

\section{TUNED EXCITATION}

The excitation winding may be tuned by a parallel capacitor. The nonlinear tank circuit yields the required high excitation current peaks, driving the core further into saturation, whereas the excitation current rms value is low. The resonance condition depends not only on frequency, but also on the generator amplitude. The current delivered by the generator into the tank remains sinusoidal. Before the onset of saturation in the core, the impedance of the excitation winding is high and the generator current mainly charges the tuning capacitor. At the onset of saturation, the impedance falls due to the low permeability of the saturated core. The parallel tuning capacitor is discharged into this low impedance and causes high excitation peaks. The analytic solution of this nonlinear circuit is given in [18]. A peak-peak/rms ratio of 5.2 was achieved for an excitation frequency of $25 \mathrm{kHz}$. Decreasing the excitation winding resistance can increase this factor to 7.9 [19].

In case of a $20-\mathrm{kHz}, 6-\mathrm{V}$ rms sinewave from the $50-\Omega$ generator, the value of the tuning capacitor is $470 \mathrm{nF}$. A 930-mA p-p excitation current is achieved with the same power delivered by the generator as for the untuned sensor. Figs. 4 and 5 show the corresponding waveforms for $I=0$ and $I=1 \mathrm{~A}$, respectively.

Notice that the generator current is a sinewave and that the large peaks in the excitation are delivered by the charged capac- 


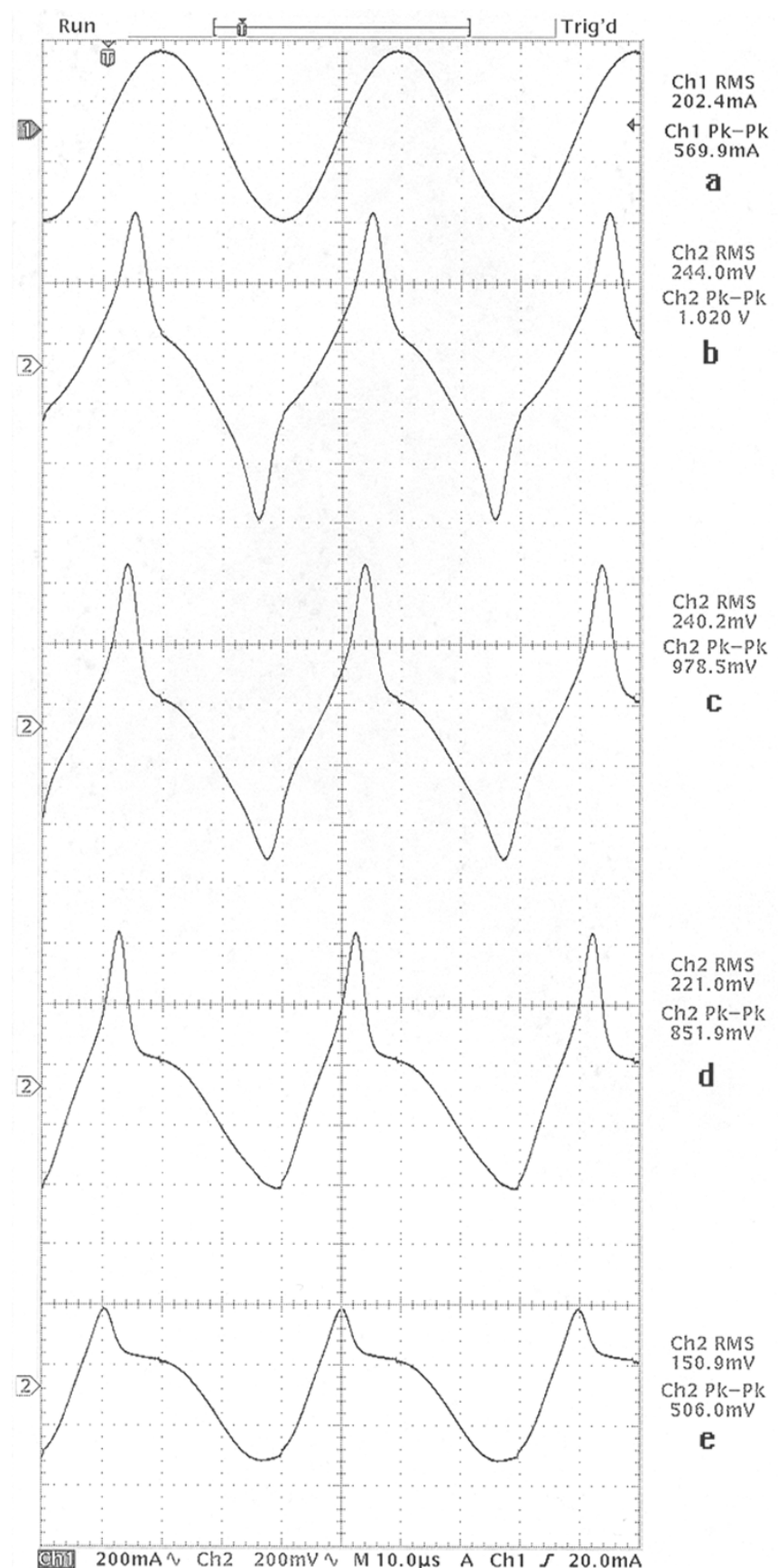

Fig. 2. Untuned sensor. (a) Excitation current (200 mA/div) and (b)-(e) induced voltage $(200 \mathrm{mV} / \mathrm{div})$ for increasing measured current: (b) $I=0$; (c) $I=1 \mathrm{~A}$; (d) $I=2 \mathrm{~A}$; (e) $I=3 \mathrm{~A}$.

itor. The magnetic field energy is later partially recycled into the capacitor.

The flux waveform and working B-H loop in Fig. 6 show that the core is deeply saturated in this case. In the tuned mode, the perming effect and hysteresis are lower and the linear range is extended.

The tuning effect is highly nonlinear: Doubling the tuning capacitor increases the current amplitude only by $10 \%$. The resonant maximum is flat, and the resonance frequency is not very dependent on the capacitor value, unlike the fluxgate sensors.

Resonance cannot be achieved for capacitor values less than $100 \mathrm{nF}[2]$.

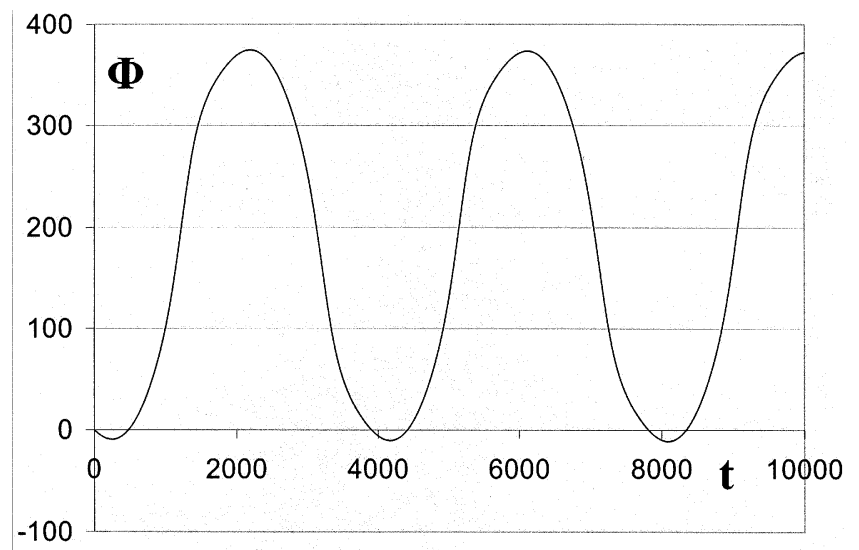

a)

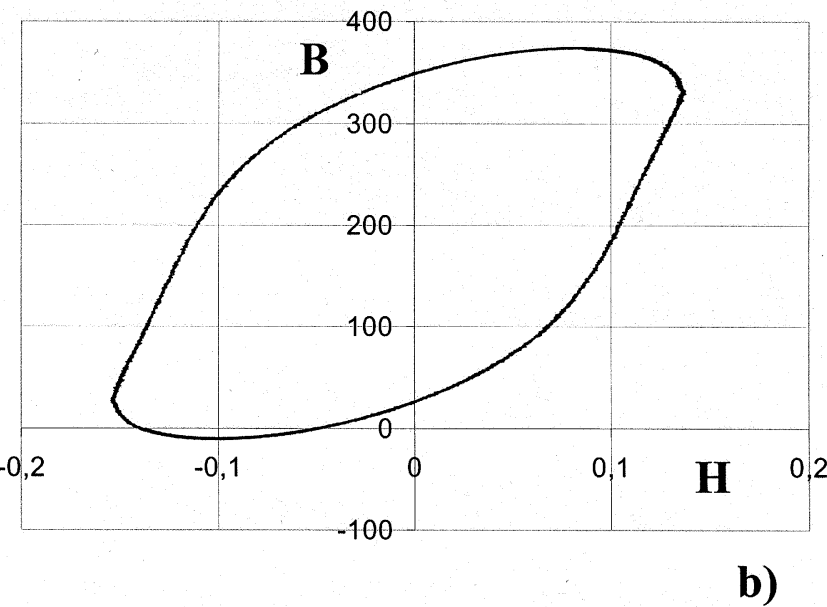

Fig. 3. Untuned sensor, no measured current I (a) flux waveform and (b) B-H working loop (arb. units).

Modest improvement of the excitation efficiency can be achieved by reducing the excitation coil resistance, which was simulated by using an excitation winding with $0.4-\mathrm{mm}$-diameter copper wire. The maximum peak-peak current achieved was $1500 \mathrm{~mA}$. Table II lists the excitation parameters achieved; note that the rms value of the current delivered by the generator $\left(I_{\text {grms }}\right)$ is practically constant. The tuning efficiency (given as the ratio between the excitation peak-peak current and generator rms current, $I_{\text {exc }}$ peak-peak $/ I_{\text {gen }} \mathrm{rms}$ ) is higher: up to 8 instead of 5 for the PCB winding. For comparison, the value achieved for standard fluxgate sensors was 28 (1-A peak-peak excitation current for $35-\mathrm{mA}$ rms generator current), which indicates that high coil resistance is only one reason for the low-quality factor in this circuit. The other reason is low inductance due to the small volume of the core and low permeability. Further development will concentrate on increasing the excitation efficiency by improving the magnetic properties of the deposited permalloy. Another possibility is to use layers of amorphous magnetic material embedded in the PCB structure [15].

Excitation by a squarewave voltage is more advantageous for low-power operation, but the sensor signal processing is more complicated. Chiesi et al. [20] use short current pulses for excitation. A recent novel solution is to employ another saturated inductor in series with the sensor excitation [21]. 

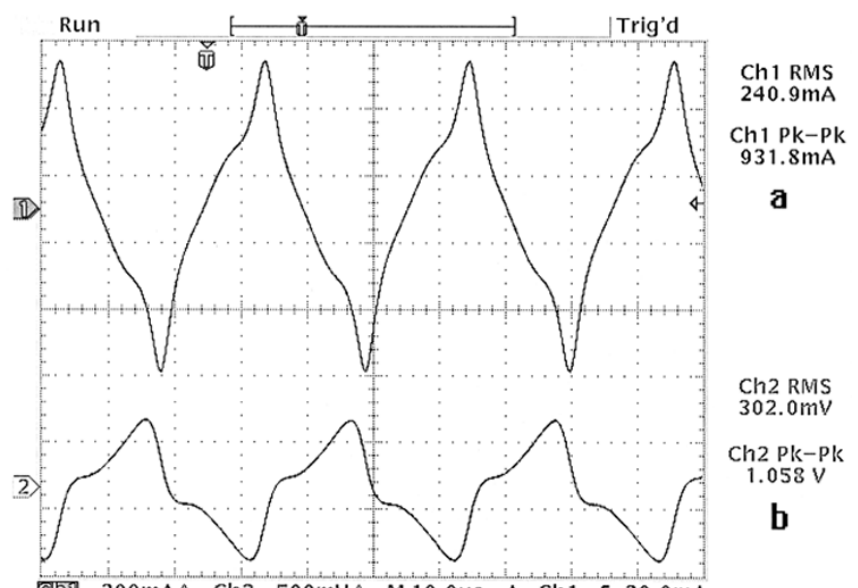

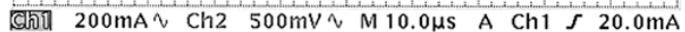

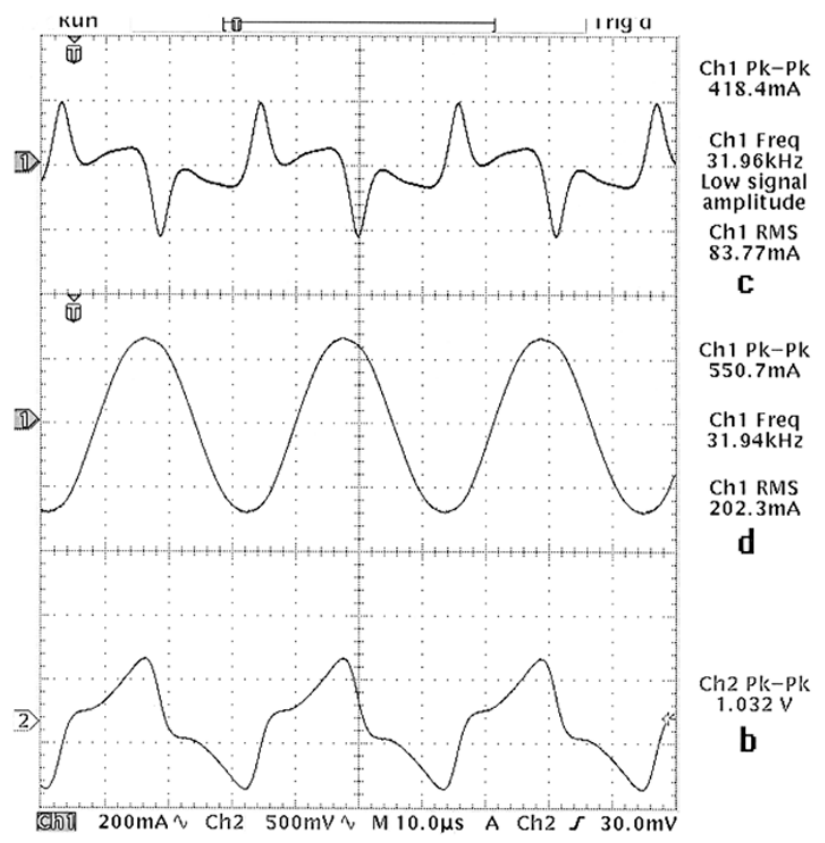

Fig. 4. Sensor, tuned by parallel capacitor, for measured current $I=0$. (a) Excitation current $(200 \mathrm{~mA} / \mathrm{div})$. (b) Induced voltage $(500 \mathrm{~mA} / \mathrm{div})$. (c) Capacitor current $(500 \mathrm{~mA} / \mathrm{div})$. (d) Total current delivered by the generator (500 mA/div).

\section{SENSOR CHARACTERISTICS}

Sensor characteristics were measured by a digital lock-in amplifier SR 830 in a LabVIEW environment. The reference was set to the second harmonic; phase was always adjusted for maximum sensitivity.

Fig. 7 shows the sensorcharacteristics as afunction of the excitation frequency for fixed values of the tuning capacitor $(470 \mathrm{nF})$ and generator amplitude (10 V p-p for unloaded generator). Although the resonance peak at $50 \mathrm{kHz}$ is broad, the stability of the open-loop sensitivity is not sufficient due to the temperature dependence of the core permeability. When current feedback is used, the sensitivity is dominated mainly by the properties of the feedback coil. Sensitivity stability of the order of $100 \mathrm{ppm} / \mathrm{K}$ is achievable.

The open-loop sensor characteristics has a linearity error of $10 \%$ for a current range of $1 \mathrm{~A}$. Again, dramatic improvement can be achieved by using current feedback.

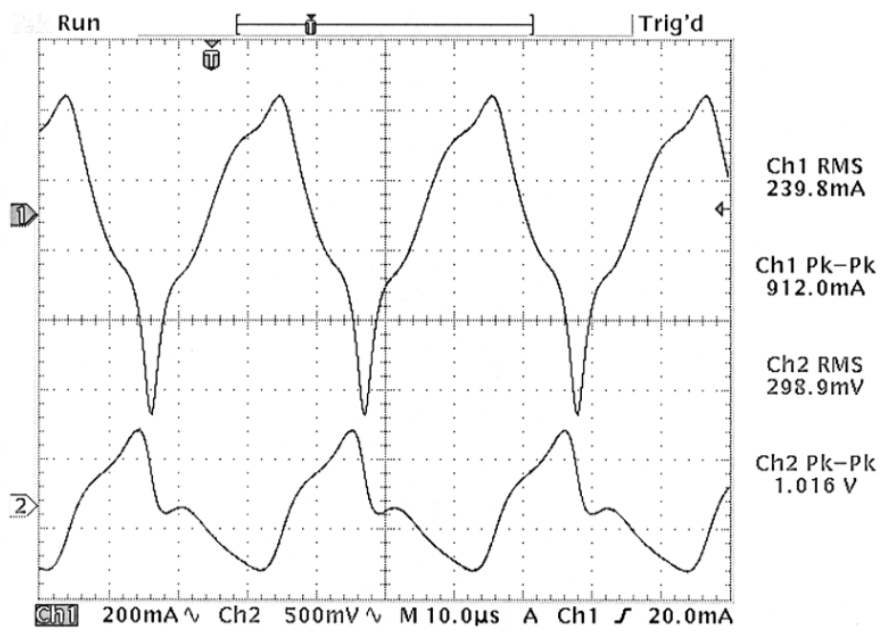

Fig. 5. Sensor, tuned by parallel capacitor, $I=1 \mathrm{~A}$ : Excitation current (upper trace, $200 \mathrm{~mA} / \mathrm{div}$ ) and induced voltage (lower trace, $500 \mathrm{mV} / \mathrm{div}$ ).
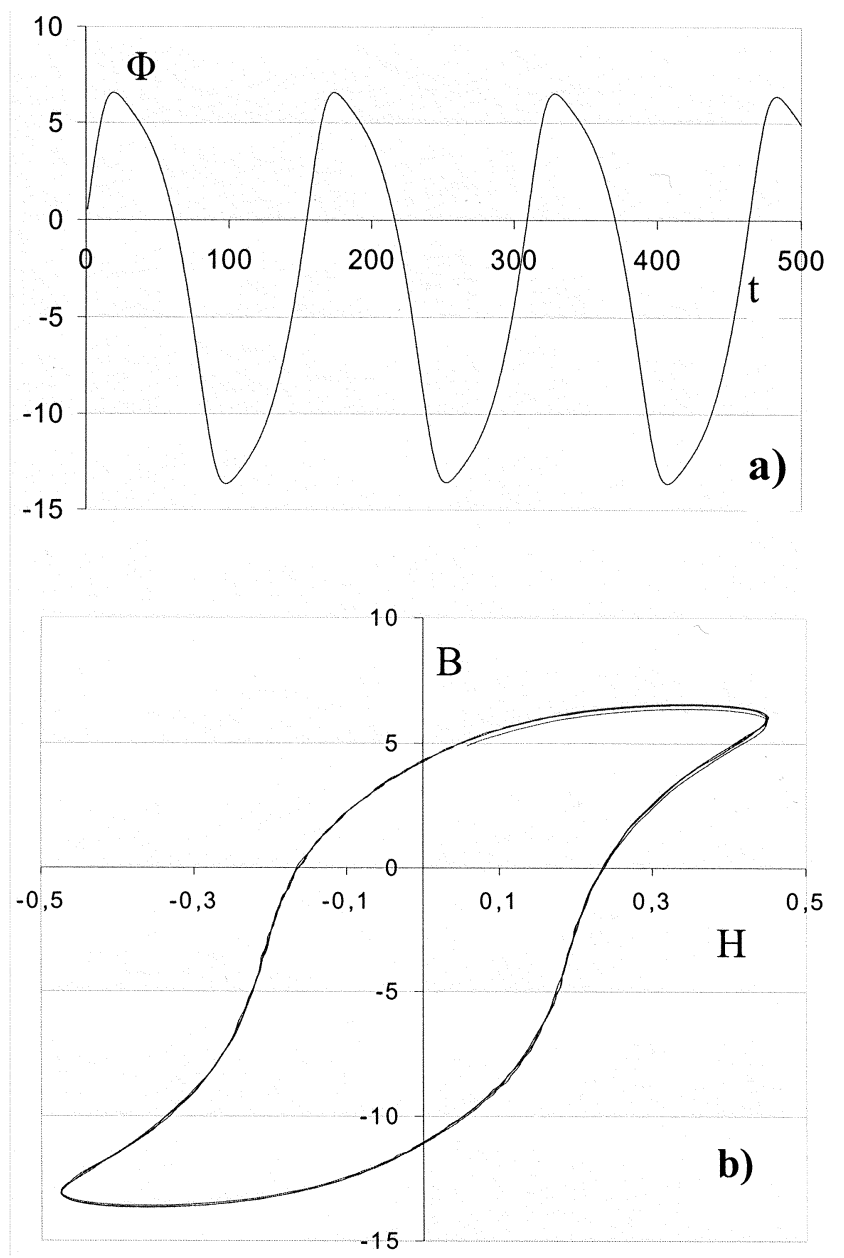

Fig. 6. Flux waveform and working B-H loop for tuned sensor (arb. units).

The sensor sensitivity can be increased by using multiple turns of the measured conductor. The associated increase in equivalent insertion impedance is usually not a problem, as the core cross-section is very low. This situation is illustrated in Fig. 8: Increased sensitivity is accompanied by a reduced full-scale range for open-loop linear operation. When using the sensor in the compensated (feedback) mode, it is important to ensure that the output (in open loop) does not change sign for 
TABLE II

EXCITATION PARAMETERS ACHIEVED WITH 700- AND 40- $\mu \mathrm{m}$ COILS

\begin{tabular}{|l|l|l|l|l|l|l|}
\hline $\mathrm{C}$ & $\mathrm{I}_{\text {ex p-p }}$ & $\mathrm{f}$ & $\mathrm{I}_{\text {ex }} \mathrm{rms}$ & $\mathrm{I}_{\text {ex p-p }} / \mathrm{I}_{\text {ex }} \mathrm{rms}$ & $\mathrm{I}_{\mathrm{g}} \mathrm{rms}$ & $\mathrm{I}_{\text {ex p-p }} / \mathrm{I}_{\mathrm{g}} \mathrm{rms}$ \\
$\mathrm{nF}$ & $\mathrm{mA}$ & $\mathrm{kHz}$ & $\mathrm{mA}$ & - & $\mathrm{mA}$ & - \\
\hline
\end{tabular}

40 turns $(\mathrm{PCB}), \mathrm{R}=700 \mathrm{~m} \Omega$

\begin{tabular}{|l|l|l|l|l|l|l}
\hline 0 & 540 & -- & 194 & 2.78 & 194 & 2.78 \\
\hline 100 & 675 & 43 & 213 & 3.17 & 201 & 3.36 \\
\hline 200 & 780 & 35 & 221 & 3.54 & 202 & 3.86 \\
\hline 470 & 912 & 28 & 240 & 3.8 & 200 & 4.56 \\
\hline 940 & 1030 & 25 & 269 & 3.82 & 200 & 5.2 \\
\hline
\end{tabular}

40 turns ( $\mathrm{Cu}$ wire, $\mathrm{d}=0.5 \mathrm{~mm}), \mathrm{R}=40 \mathrm{~m} \Omega$

\begin{tabular}{|l|l|l|l|l|l|l}
\hline 470 & 1250 & & 384 & 3.25 & 188 & 6.65 \\
\hline 940 & 1500 & & 442 & 3.4 & 190 & 7.89 \\
\hline
\end{tabular}

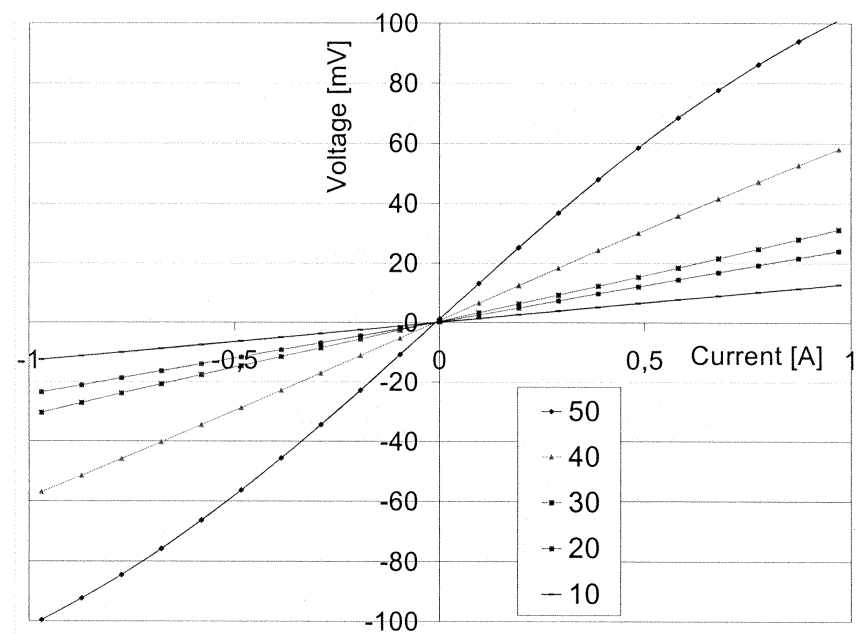

Fig. 7. Sensor characteristics as a function of frequency (in kilohertz). The excitation tuning capacitor is $470 \mathrm{nF}$.

large measured values, because this would cause instability of the loop if the sensor is subjected to short high current pulses.

\section{CONCLUSION}

A simple dc/ac current sensor constructed in PCB technology has been described. The sensitivity achieved was $100 \mathrm{mV} / \mathrm{A}$, and open-loop linearity is $10 \%$ in the 1-A range. A single 40 -turn winding was created by copper PCB layers and vias and was used both for excitation and for sensing. Current feedback can increase the linear range, improve linearity, and increase the stability of the sensitivity. The same winding can be used for

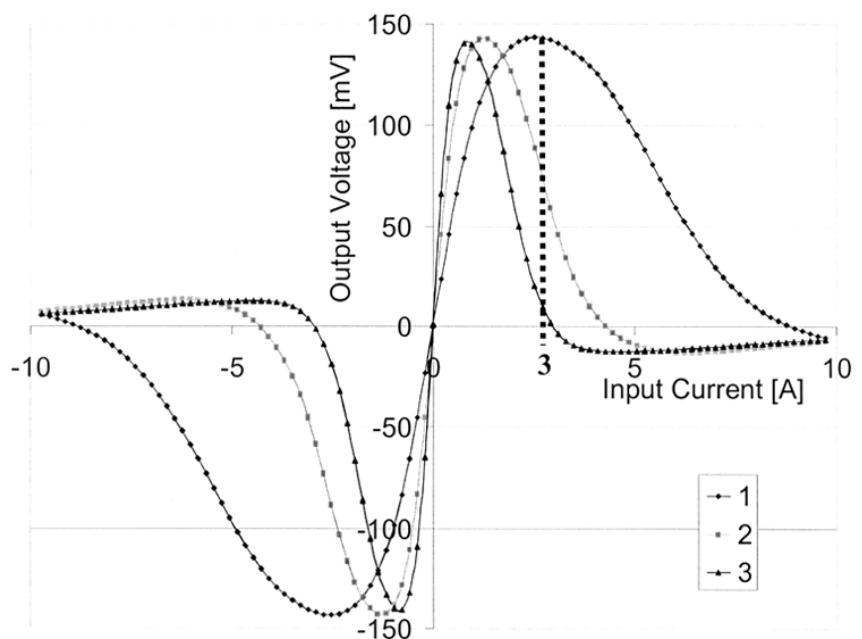

a)

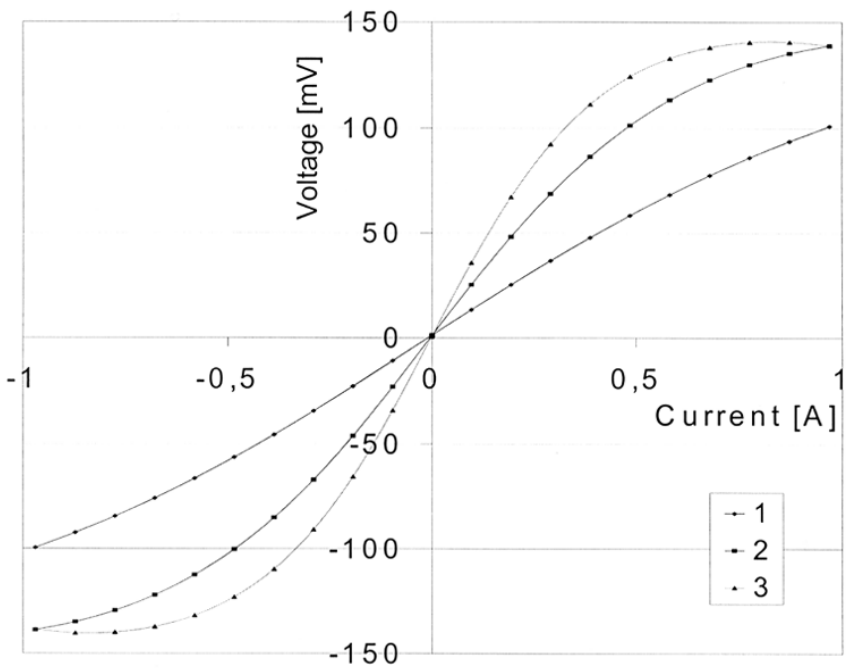

b)

Fig. 8. Sensor characteristics for one, two, and three turns of the measured conductor (a) for high currents and (b) for the 1-A range.

feedback. The main limiting factor both for the feedback current amplitude and for the excitation efficiency is the dc resistance of the winding. Experiments with amorphous cores have shown that sensitivities up to $400 \mathrm{mV} / \mathrm{A}$ can be achieved. Developed low-cost sensors are suitable for monitoring dc currents in switching-mode power supplies and in power management systems for cars, solar batteries, and other applications.

\section{REFERENCES}

[1] K. Iwansson, G. Sinapius, and W. Hoornaert, Measuring Current, Voltage and Power. New York: Elsevier, 1999.

[2] P. Ripka, Ed., Magnetic Sensors and Magnetometers. London, U.K.: Artech House, 2001.

[3] B. Drafts and F. W. Bell. A tutorial on the new magnetoresistive technology current sensor. [Online]. Available: http://fwbell.com

[4] R. Bazzocchi et al., "Interference rejection algorithm for current measurement using magnetic sensor arrays," in Proc. Sens. Actuators, Eurosensors XIII, The Hague, The Netherlands, pp. 895-898.

[5] J. T. Scoville and P. I. Petersen, "A low-cost multiple hall probe current transducer," Rev. Sci. Instrum., vol. 62, pp. 755-760, 1991.

[6] P. Kejík, P. Ripka, P. Kašpar, and K. Draxler, "Precise dc current sensors," in Proc. Instrumentation and Measurement Technology Conf., Brussels, Belgium, 1996, pp. 1479-1483. 
[7] Datasheets. NVE Corporation. [Online]. Available: http://www.nve.com

[8] J. L. Prieto, N. Rouse, N. K. Todd, D. Morecroft, J. Wolfman, J. E. Evetts, and M. G. Blamire, "Integrated magnetic field sensor based on magnetoresistive spin valve structures," Sens. Actuators A, vol. 94, pp. 64-68, 2001.

[9] M. Vieth, W. Clemens, H. van den Berg, G. Rupp, J. Wecker, and M Kroeker, "Contactless current detection with GMR sensors based on an artificial antiferromagnet (AAF) subsystem," Sens. Actuators A, vol. 81, pp. 44-48, Apr. 2000.

[10] P. Ripka, M. Tondra, J. Stokes, and R. Beech, "AC-driven AMR and GMR magnetoresistors," Sens. Actuators A, vol. 76, pp. 225-230, 1999.

[11] Y. S. Didosyan, H. Hauser, and J. Nicolics, "Magneto-optical current sensor of high bandwidth," Sens. Actuators A, vol. 81, pp. 263-267, 2000.

[12] A. Pross, C. Lewis, and T. Hesketh, "A low cost analogue current transducer," Sens. Actuators A, vol. 76, pp. 72-77, 1999.

[13] Vacuumschmelze, Current Sensors Magnetic Field Detector (PB 151-4). Hanau, Germany: Vacuumschmelze GMBH.

[14] Y. Fujiyama, Y. Yamada, H. Kikuchi, M. Yamaguchi, and K. I. Arai, "A fail-safe thin film current sensor using a flux saturable ring core," IEEE Trans. Magn., vol. 33, no. 5, pp. 3406-3408, Sep. 1997

[15] O. Dezuari, E. Belloy, S. E. Gilbert, and M. A. M. Gijs, "Printed circuit board integrated fluxgate sensor," Sens. Actuators A, vol. 81, pp. 200-203, 2000.

[16] E. Belloy, S. E. Gilbert, O. Dezuari, M. Sancho, and M. A. M. Gijs, "A hybrid technology for miniaturised inductive device applications," Sens. Actuators A, vol. 85, no. 1-3, pp. 304-309, Aug. 2000.

[17] S. O'Reilly et al., "New integrated planar magnetic cores for inductors and transformers fabricated in MCM-L technology," in Proc. IMAPS-US, Chicago, IL, Oct. 1999, pp. 493-498.

[18] P. Ripka and W. Hurley, "Excitation tuning of fluxgate sensors," in Proc. Instrumentation and Measurement Technology Conf., 2002, pp. 677-680.

[19] P. Ripka, M. Duffy, S. O'Reilly, and W. G. Hurley, "PCB-integrated current sensor," in Proc. JMW, Cardiff, U.K., 2001, pp. 89-89.

[20] L. Chiesi, P. Kejik, B. Janossy, and R. S. Popovic, "CMOS planar 2D micro-fluxgate sensor," Sens. Actuators A, vol. 82, no. 1-30, pp. 174-180, 2000

[21] S. C. Tang, M. C. Duffy, P. Ripka, and W. G. Hurley, "Excitation circuit for fluxgate sensor using saturable inductor," Sens. Actuators A, vol. 113, no. 2 , pp. 156-165, Jul. 2004.

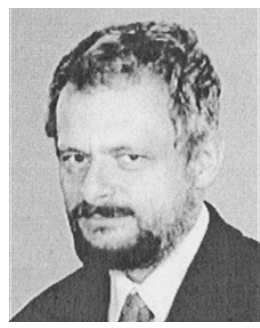

Pavel Ripka (M'00) received the engineering degree, the C.Sc. degree (equivalent to a Ph.D.), the Docent degree, and the Professor degree from Czech Technical University, Prague, Czech Republic, in 1984 1989, 1996, and 2002, respectively.

From 1991 to 1993 , he was a Visiting Researcher with the Danish Technical University, and during 2001, he held the Marie Curie Experienced Researcher's Fellowship with the National University of Ireland, Galway. He is currently with the Department of Measurement, Faculty of Electrical Engineering, Czech Technical University, as a Professor, lecturing in measurements, engineering magnetism and sensors. His main research interests include magnetic measurements and magnetic sensors, especially fluxgate.

Dr. Ripka is a member of the Elektra Society, Czech Metrological Society, Czech National IMEKO Committee, Eurosensors Steering Committee, and an Associate Editor of the IEEE SENSORS JOURNAL. He was General Chairman of the Eurosensors XVI Conference held in Prague in 2002.

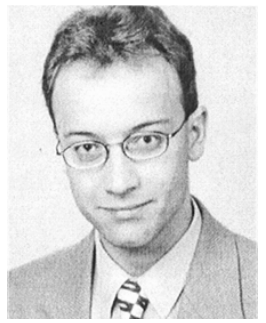

Jan Kubik was born in Pardubice, Czech Republic, in 1979. He received the Ing. degree (M.Sc. equivalent) in electrical engineering from Czech Technical University, Prague, in 2003. He is currently pursuing the $\mathrm{Ph} . \mathrm{D}$. degree in electrical engineering at Czech Technical University.

His research interests include construction of magnetic sensors, magnetic sensors calibration, and error correction methods.

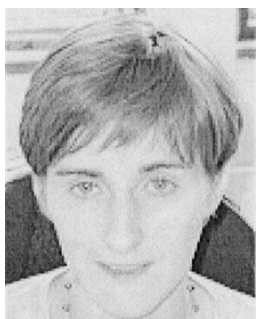

Maeve Duffy was born in Monaghan, Ireland. She received the B.E. degree (Hons.) in electronic engineering and the Ph.D. degree in planar magnetics from the National University of Ireland, Galway (NUIG), in 1992 and 1997, respectively.

She was a Research Officer with PEI Technologies at the National Microelectronics Research Centre, Cork, Ireland, from 1997 to 2001. She is currently a Lecturer with the Department of Electronic Engineering, NUIG. Her main research interests include modeling and design of magnetic components, including planar magnetics and magnetic sensors.

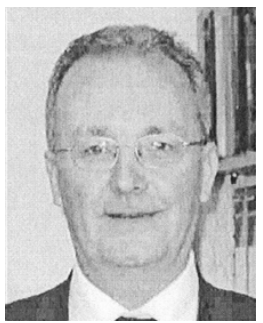

William Gerard Hurley (M'77-SM'90) was born in Cork, Ireland. He received the B.E. degree (first class honors) in electrical engineering from the National University of Ireland, Cork, the M.S. degree in electrical engineering from the Massachusetts Institute of Technology (MIT), Cambridge, and the Ph.D. degree from the National University of Ireland, Galway (NUIG), in 1974, 1976, and 1988, respectively.

He was with Honeywell Controls in Canada as a Product Engineer from 1977 to 1979 . He was a Development Engineer in transmission lines at Ontario Hydro from 1979 to 1983 . He lectured in electronic engineering at the University of Limerick, Ireland, from 1983 to 1991 and is currently Vice President and Professor of Electrical Engineering with the NUIG. He was a visiting professor at the MIT in 1997/1998. He is the Director of the Power Electronics Research Center, Galway. Research interests include high-frequency magnetics, power quality, automotive electronics and alternative energy systems.

Dr. Hurley received a Best Paper Prize from the IEEE TRANSACTIONS ON POWER ELECTRONICS in 2000. He is a Fellow of the Institution of Engineers of Ireland and a member of Sigma Xi. He has served as a member of the Administrative Committee of the Power Electronics Society of the IEEE and was General Chair of the Power Electronics Specialists Conference in 2000.

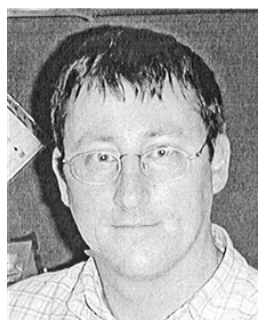

Stephen O'Reilly received the B.S. degree (Hons.) in electrical engineering from the National University of Ireland, Cork, and the M.S. degree in engineering science from the National Microelectronics Research Centre (NMRC), National University of Ireland, in 1993 and 1995, respectively.

Since joining NMRC, he has been extensively involved in multilayer thick-film and PCB techniques, as well as electrical testing, simulation and characterization of planar magnetic components. From 1996 to 2000, he was project manager at NMRC for the EU-funded COMPRISE project, which focused on integrating passive components into multilayer printed circuit boards. Along with his colleagues, he was awarded a patent for his work on this project. He is currently working on the EU-funded TUBA project where he is designing planar resonant circuits for the inductive powering of biomedical implants.

Mr. O'Reilly is a member of IMAPS. 